\title{
Saving the Fundaments: Impact of a Military Coup on the Sudan Health System
}

\author{
Alhadi K. Osman ${ }^{1,2,3}$, Mona Ibrahim ${ }^{4}$, Karrar Karrar ${ }^{5}$ Hassan Salih ${ }^{6,3}$, Mohamed \\ Elsheikh ${ }^{7,8}$ \\ ${ }^{1}$ Julius Global Health, University Medical Center Utrecht, Utrecht, The Netherlands \\ ${ }^{2}$ Federal Ministry of Health, Sudan \\ ${ }^{3}$ The National Ribat University, Sudan \\ ${ }^{4}$ University of Oxford, United Kingdom \\ ${ }^{5}$ Save The Children-UK, United Kingdom \\ ${ }^{6}$ Johns Hopkins University, Bloomberg School of Public Health, United States of America \\ ${ }^{7}$ University of Sussex, United Kingdom \\ ${ }^{8}$ Mycetoma Research Center-University of Khartoum, Sudan \\ ORCID:
}

Alhadi K. Osman: https://orcid.org/0000-0003-0738-103X

Mohamed Elsheikh: https://orcid.org/0000-0001-9474-4219

Mona Ibrahim: https://orcid.org/0000-0001-8070-0530

Corresponding Author: Alhadi

K. Osman; email:

alhadikhogalios

man@gmail.com

Received 24 November 2021

Accepted 16 December 2021

Published 31 December 2021

Production and Hosting by

Knowledge E

(ㄷ) Alhadi K. Osman et

al.. This article is distributed under the terms of the

Creative Commons

Attribution License, which

permits unrestricted use and

redistribution provided that the original author and source are credited.

Editor-in-Chief:

Prof. Mohammad A. M. Ibnouf

\section{Abstract}

Military coups are not uncommon occurrences, particularly in developing nations where political systems might be less firmly entrenched or still evolving. Developments of this nature can often have profound implications for the affected nation's healthcare systems, both in the immediate aftermath and over the longer term. This paper narrates some notable consequences of political instability on the national health system, particularly placing them in the context of the military coup in October 2021 - emphasizing the context behind the political turbulence, its acute and direct consequences, and the possible long-term legacies of political shocks on the already overwhelmed health system. As a descriptive piece, this narrative does not only look at the impact of the military coup on hospitals, but further considers the different dimensions of the healthcare system as defined by the WHO, therefore reflecting the wider implications on health funding from multi-laterals, service delivery, human resource availability, and medical and vaccine supply chains in Sudan.

Keywords: healthcare system, military coup, health, political, impact, Sudan

\section{Introduction}

Military coups are not uncommon in low- and middle-income countries; for example, there have been 10 military coups in African countries in the past five years alone [1]. The most recent occurred on October 25, 2021, when the Sudanese army deposed the transitional government (the $17^{\text {th }}$ such event in Sudan since its independence in 1956). This article uses this event as the focal lens to examine the impact of military coups on Sudan's healthcare system, exploring some of the longer-term implications (such as the 
availability of financial and human resources, and the acquisition of new medicines and technologies).

\section{A leadership vacuum}

The negative results of a leadership vacuum have been well-documented. High governance and leadership turnover-rates and a lack of succession planning can result in disruption to healthcare organizations and an inability to create and sustain change [1]. This train of events was visible in the immediate aftermath of the October coup in Sudan, which saw the dismissal of both the Federal Minister and the undersecretary of the Federal Ministry of Health (FMOH). These two positions are critical to the management of the Sudanese health systems, monitoring the progress of the different functions, coordinating partners and stakeholders locally and globally, and working toward the goal of achieving universal health coverage in Sudan (Figure 1). The removal of these two officials had a significant negative impact on these processes.

Changes in healthcare leadership can result in drastic changes in healthcare policies, which can be driven by individual interests rather than systematic, resilient, and evidence-based priorities. The Sudanese healthcare system has experienced this on multiple occasions; in the last three years alone the $\mathrm{FMOH}$ has had three ministers, four undersecretaries, and numerous changes on the general directorates' level. These high-level staffing changes trickle down to the mid-level leadership, which sees a further series of turnovers. In a hurried and unplanned change, such as occurs in the aftermath of a military coup, international relations can experience a period of turmoil as foreign organizations involved in healthcare are unsure of who to contact. This intensifies the strategic and operational challenges facing a new government and healthcare leadership.

\section{Interrupted funding and donor insecurity}

Financing healthcare services is often one of the greatest challenges in the months following a military coup and change in government. In Sudan, this difficulty will perhaps be intensified due to pre-existing tensions experienced by the previous government which faced rising out-of-pocket expenditures and falling government financial contributions (leaving the healthcare sector increasingly reliant on donor contributions). In addition, the country was already undergoing sweeping financial reforms which resulted in economic stresses and rising inflation - these factors are likely to be intensified 
as some channels of financial support from the international community have been temporarily frozen in the wake of the military coup.

The USA alone has already suspended over USD 700 million of direct assistance to Sudan's government. Developments such as this make it imperative that the new government is established and stabilized as swiftly as possible, in order to regain foreign donor trust and re-open funding channels for the healthcare systems. In the case of Sudan, there is the added concern that the country's suspension from the African Union might also disqualify it for receipt of healthcare funding in the foreseeable future; for example, membership in the African Union is a prerequisite to receiving the acquisition fund for COVID-19 vaccination (2).

Although independent funders and development agencies like UNICEF continue to deliver assistance in eastern and southern Sudan, failure to transition to civilian leadership will put the financial security of the healthcare system at risk. An already underfunded and overstretched system like Sudan's is in jeopardy of losing the existing infrastructure, burdening the future administration with overwhelming recovery and repair costs.

\section{Suspended service delivery}

Service delivery interruption is typically one of the most immediate consequences of a military coup or unexpected change in government as communications systems and power infrastructure can be disabled, and healthcare workers are often being unable to make it to their workplaces (due to unrest in the streets, the closure of transport networks, or blockading activities by various factions). For example, in the 2021 Sudanese coup, workers in Khartoum and other major cities were unable to get to the healthcare facilities owing to creation of roadblocks by a group opposing the coup.

Service delivery can often suffer further interruptions as the existing leadership is removed and a new leadership takes time to emerge. This can be exacerbated by similar developments in adjacent social safety nets, education systems, and public services. In line with Sudan's history of an interrupted healthcare system functionality in times of political stress, most healthcare services (with the exception of emergency services and critical care) were suspended in the October 2021 military coup.

Thirdly, service delivery issues are further intensified by the pronounced urban rural divide in Sudan. Initially stresses are greater in cities which bore the brunt of the damage in the wake of the coup, but as financial stresses intensify, the rural areas will see an increased impact owing to the growing scarcity of medical resources combined with 
existing pressures stemming from the deteriorating socioeconomic determinants of health in rural areas. In the case of the 2021 coup, the damage to healthcare service delivery is very acute in Khartoum and other big cities perhaps due to the higher rate of resistance in these educated, urban areas. However, over time, as financial stresses intensify, the rural areas will see an increased impact owing to the growing scarcity of medical resources combined with existing pressures stemming from the deteriorating socioeconomic determinants of health in rural areas.

Finally, there is a high possibility that less attention will be given to illnesses that have a history of being overlooked - such as services linked to mental health, reproductive health, and other neglected tropical diseases. This will undoubtedly widen existing health disparities across the country. While the coup is an acute event, these consequences will likely prevail for the foreseeable future.

That being said, if properly planned and efficiently implemented, a military coup does not necessarily negatively impact the healthcare system. For example, in Guinea's most recent military takeover, healthcare services were not interrupted by the coup [4], and the COVID vaccine rollout remained intact [5]

\section{Diminishing human resources for health}

On one side, medical doctors are being targeted following coups; well-educated, relatively affluent, white-collar individuals, health professionals can often play a significant role in local and national politics. In Myanmar, for example, reports suggested that doctors are being dismissed from their posts, arrested, or going into hiding in fear for their lives following the coup of 2021 [6]. In Sudan, the participation of health cadres in political disobedience, and the treatment of injured protesters is seen provocative to some army soldiers; therefore, doctors and other healthcare professionals become target to the subdue.

Following the coup, medical doctors have been working under stressful conditions, especially as they continue to be first responders to events with mass casualties, extensive traumatic injuries, and serious concerns for patient confidentiality. This is difficult to handle considering their under-resourced and limited capacities.

However, medical doctors and other healthcare staff are individuals living within a larger society, they interact with the social and political changes in that community. The increasing restriction of civil freedoms and violation of human rights following the coup may well discourage doctors and other specialized professionals from staying in Sudan - it may further discourage Sudanese professionals in the diaspora from returning. As a 
result, catastrophic shortage in the health workforce may remain as a challenge in the coming years, given the compiling struggles to meet basic healthcare demands. Another critical dimension of the human resources in health is the disruption of academic and professional health training, which will undoubtedly have a knock-on effect on the health workforce and capacity over at least the coming year.

\section{Medical products, vaccines, and other supply chain dis- ruptions}

Medicines and related technologies are central to any functioning healthcare system. In situations of increased political fragility, access to pharmaceutical products can proxy healthcare access. The vast uncertainty due to the military coup will typically impact all four critical domains of the medical supply chain - availability, accessibility, affordability, and acceptability. In Sudan, there is limited domestic resources for medical products manufacturing and supply chain; despite the country's sizable domestic generic pharmaceutical industry, $<15 \%$ of licensed medicines are manufactured locally, meaning the healthcare system is heavily reliant on imports [7]. In short terms, there will be less pressure, as the WHO delivered 283 tons of medicines and health supplies to Khartoum just a day before the coup [8]; however, the continuity of drug procurement could be jeopardized if the current state is prolonged.

The historic economic sanctions, currency devaluation, and the state of hyperinflation has limited the purchasing power of the government and balanced finite hard currency reserves. The heavy reliance on imports makes the healthcare system vulnerable to supply chain disruptions and it needs access to large volumes of hard currency (e.g., USDs and euros) to procure pharmaceutical commodities internationally. The coup may affect the internal production and external import of medical commodities.

Further, the shipment of medications through land and sea has been halted. For example, the shutdown of Port Sudan-Khartoum roads by the residents in Eastern Sudan has directly hindered the distribution of imported medicines.

\section{Future considerations}

It is crucial to consider the impacts of political instability on emerging healthcare systems which come at the cost of increased morbidity and mortality rates. There is a need for more understanding of the political determinants of health in Sudan. Further critical exploration must be done on the impact of political instability in Sudan, particularly 


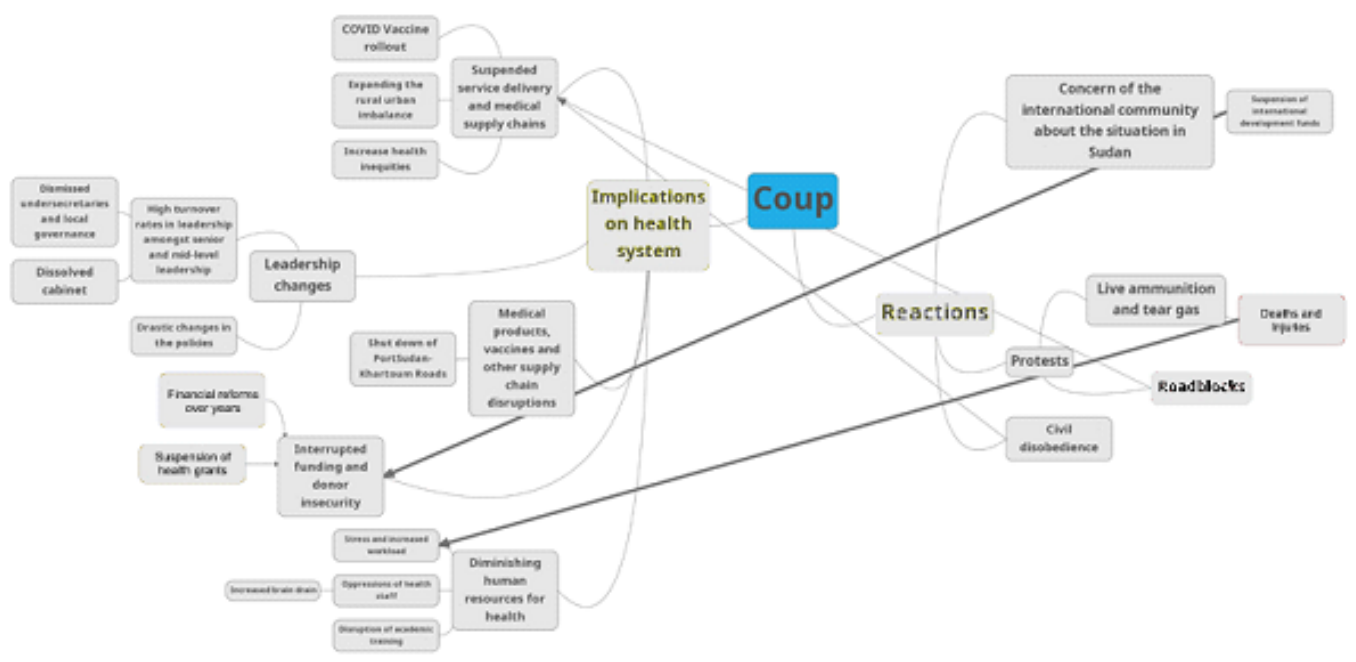

Figure 1: A theory of change in the potential impact of the military coup in October 2021 on the Sudanese healthcare system.

in the healthcare system. Also, there might be a need for innovative financing and resource mobility systems that can resist the impact of political and economic shocks to help healthcare leadership, finance, and operating systems be resilient to political instability.

In conclusion, this article highlighted several potential challenges that the Sudanese coup might inflict on the healthcare system in Sudan, these challenges include leadership vacuum, interrupted health funding, suspended service delivery, diminished human resources for health, and disrupted medical supply chain.

\section{Notes}

Abdel Fattah al-Burhan, the commander of the Sudanese army and the head of the transitional sovereign council, announced a halt in the transition phase to democracy stating the urgent need for "constitutional correction." This entailed the dismissal of the leading governing bodies, the prime minister, four ministers, leading politicians; some activists were also reported to have been taken into custody at undisclosed locations. A state of emergency was declared, and the transitional sovereign council was immediately suspended. Detainees, including the deposed prime minister Abdalla Hamdok, were not seen or heard for just over one month. According to the Central Committee of Sudan Doctors (CCSD), at least 40 people were killed and more than 400 injured during this period as a result of live ammunition, violent encounters, and tear gas bombs against civil protestors. Simultaneously, the country experienced a militaryordered nationwide blackout, halting communications, networks, and internet across 
the country. As a result, many in the international health community have warned that the fatality and morbidity rates may have been under-reported.

Over the past decade, the healthcare system in Sudan has been challenged many times, including: the country's separation from South Sudan and the immense loss of healthcare funding that followed; the many political movements against Omar Albashir's presidency and their associated political instability - including the successful revolution in 2019; and the twin burden of the COVID-19 pandemic in conjunction with continuous mass protests, pushing the healthcare system to the verge of collapse. The country continues to be burdened with chronic political unrest.

\section{References}

[1] McDonagh, K. J., Bobrowski, P., Hoss, M. A. K., et al. (2014). The leadership gap: ensuring effective healthcare leadership requires inclusion of women at the top. Open Journal of Leadership, vol. 03, no. 02, pp. 20-29.

[2] Reliefweb. (2021 August 5). Africa announces the rollout of $400 \mathrm{~m}$ vaccine doses to the African Union Member States and the Caribbean. Reliefweb. Retrieved from https://reliefweb.int/report/world/africa-announces-rollout-400mvaccine-doses-african-union-member-states-and-caribbean

[3] Rocha, I. C., Cedeño, T. D., Pelayo, M. G., et al. (2021). Myanmar's coup d'état and its impact on COVID-19 response: a collapsing healthcare system in a state of turmoil. BMJ Military Health. Retrieved from https://militaryhealth.bmj.com/content/ early/2021/05/21/bmjmilitary-2021-001871

[4] Adepoju, P. (2021 September 7). Will Guinea's coup interrupt the country's health responses? Devex. Retrieved from https://www.devex.com/news/will-guineas-coup-interrupt-the-country-s-health-responses-101562

[5] Diallo, B. (2021 November 10). Guinea to Vaccinate children against COVID-19 in capital. World News I US News. Retrieved from https://www.usnews.com/news/ world/articles/2021-11-10/guinea-to-vaccinate-children-against-covid-19-in-capital

[6] Shepherd, A. (2021). Myanmar medics resist military coup. BMJ, vol. 372, no. March, p. n368.

[7] Diligencia. (2020 December 1). Pharmaceuticals in frontier markets: Part 3 - Sudan. Diligencia. Retrieved from https://www.diligenciagroup.com/insightsresources/pharmaceuticals-in-frontier-markets-part-3-sudan/

[8] Devi, S. (2021). Sudan coup prompts fresh health and humanitarian fears. Lancet, vol. 398, no. 10313 , p. 1790. 